\title{
Ciclos de protesto e repertório de ação do movimento indígena brasileiro entre 2009 e 2016: o caso da PEC 215
}

\section{Cycles of protest and repertoire of action of the Brazilian Indigenous movement between 2009 and 2016: the case of the PEC 215}

\section{Introdução}

A cena rodou o mundo por meio de inúmeras publicações internacionais. ${ }^{3}$ De um lado, homens e mulheres pintados com

1 Doutorando do Programa de Pós-Graduação em Ciência Política da Universidade Federal de Minas Gerais (UFMG).E-mail: <leobarros.prodep@gmail.com>.

2 A primeira versão deste artigo recebeu críticas importantes do professor doutor Marcus Abílio Gomes Pereira, docente da UFMG, e de minha colega de doutorado naquela instituição, Priscila Delgado de Carvalho, com quem tenho estimulantes discussões sobre questões indígenas. Rayza Sarmento e Maria Alice Silveira também contribuíram para a versão final deste artigo. Uma segunda versão deste trabalho foi apresentada no II Congreso Internacional Los Pueblos Indígenas de América Latina, realizado entre os dias 20 e 24 de setembro de 2016 em Santa Rosa, Argentina. O presente texto incorpora as sugestões realizadas pelos participantes daquele evento, a quem expresso meus agradecimentos. Ademais, agradeço aos importantes comentários realizados pelos dois pareceristas anônimos deste periódico, que tornaram o artigo mais refinado e denso conceitualmente. Por fim, agradeço ao apoio financeiro a mim concedido pela Coordenação de Aperfeiçoamento de Pessoal do Ensino Superior (Capes) do governo federal. Eventuais erros e omissões são de minha inteira responsabilidade.

3 A repercussão internacional pode ser conferida: a) na imprensa de língua inglesa: <http://www. bbc.com/news/world-latin-america-27598932>; <http://www.huffingtonpost.com/2014/05/28/ brazil-indigenous-protest-photos_n_5404045.html>; $\quad<$ http://www.dw.de/brazils-indigenousclash-with-police-in-anti-world-cup-protests/a-17666729>; <http://rt.com/news/161836-brazilindigenous-world-cup-protest/>; $\quad$ <ttp://www.dailymail.co.uk/news/article-2640969/Brazilsindigenous-police-clash-protest.html >; b) na imprensa alemã: <http://www.spiegel.de/panorama/ gesellschaft/fussball-wm-in-brasilien-proteste-in-brasilia-a-972075.html>; <http://www.zeit.de/ politik/ausland/2014-05/brasilien-proteste-ureinwohner $>$; $<$ http://www.focus.de/panorama/welt/ proteste-vor-wm-in-brasilien-mit-pfeil-und-bogen-ureinwohner-schiessen-auf-polizei_id_3879209. html>; c) em língua francesa: <http://www.lesoir.be/556731/article/actualite/monde/2014-05-28/ police-bresilienne-disperse-avec-des-lacrymogenes-une-manifestation-contre-mondi>. 
tradicionais padrões em preto e vermelho, vestindo cocares e colares vistosos, armados com lanças e arcos, elementos rústicos que contrastavam com suas calças jeans e seus calçados sofisticados. De outro, soldados da cavalaria do Distrito Federal em formação de ataque. Um dos manifestantes, segurando na mão um bastão, tapa o nariz enquanto chuta para longe uma bomba de gás lacrimogêneo. Correria e agressões mútuas. Um policial chega a ser ferido por uma flecha durante o confronto. ${ }^{4}$

A poucos dias da realização da Copa do Mundo de Futebol de 2014, momento em que a atenção midiática mundial voltava-se para o Brasil, assistia-se a uma manifestação de povos indígenas contra a tramitação da Proposta de Emenda Constitucional (PEC) 215/2000, que previa a retirada da competência da demarcação territorial pertencente aos povos originários da Fundação Nacional do Índio (Funai) e a transferia para o Congresso Nacional. ${ }^{5}$

Muito embora o Estado brasileiro seja considerado um dos pioneiros regionais no que tange à incorporação legal de princípios jurídicos consagradores da pluralidade étnica e cultural, o padrão de relacionamento entre este e os grupos indígenas mantém-se pouco alterado no decorrer dos últimos anos (Fajardo, 2009; Verdum, 2011). Os dados apresentados pelo relatório do Conselho Indigenista Missionário (Cimi, 2012) são inequívocos - o conjunto de dez anos de governo do Partido dos Trabalhadores (PT) em nível federal apresentou retrocessos marcantes no que tange à questão indígena. No ano de base do relatório, apenas dez terras indígenas foram homologadas pela então presidente Dilma Rousseff. Seu antecessor, por sua vez, com 79 homologações em oito anos de governo, tornou-se o presidente que menos as realizou no período

4 Mais informações em: <http://g1.globo.com/jornal-nacional/noticia/2014/05/policial-e-flechadopor-um-indio-durante-manifestacao-em-brasilia.html>. Acesso em: 25 nov. 2014.

5 Debruçar-nos-emos com maior profundidade sobre o conteúdo e sua cronologia de tramitação na sequência deste trabalho. 
pós-Constituição de 1988.6 Ademais, 450 empreendimentos levados a cabo pelo Programa de Aceleração do Crescimento (PAC) afetam direta ou indiretamente terras indígenas. No campo jurídico, a morosidade é a marca das ações que têm como objeto os procedimentos para a demarcação de terras tradicionais. ${ }^{7} \mathrm{O}$ contexto político, portanto, foi marcado por situações de tensão entre povos originários e governo brasileiro, que culminaram na emergência de protestos, tais como o anteriormente descrito.

É a história da mobilização de organizações indígenas para barrar a aprovação da referida PEC, que será objeto do presente estudo. Lançando mão de um conjunto de conceitos oriundos da teoria dos movimentos sociais, especialmente aqueles que dão conta de suas ações contenciosas, almejamos proporcionar uma primeira entrada no candente tema das relações entre os Poderes Legislativo e Executivo brasileiros e os movimentos sociais indígenas, no âmbito de nossa pesquisa de doutoramento. ${ }^{8}$ Nós situaremos o debate sobre o repertório de ação dos movimentos indígenas brasileiros

6 O Cimi monitora o processo de regularização fundiária indígena no Brasil desde 1990, contabilizando um total de 1.045 destes territórios (sejam eles em situação já regularizada, sejam em processo de regularização ou simplesmente reivindicada pelos povos indígenas, sem nenhuma providência ainda tomada). No que diz respeito ao número absoluto e à média de homologação destes territórios nos mandatos presidenciais pós-período ditatorial, o quadro é o seguinte: José Sarney homologou 67 terras indígenas, com uma média de 13 por ano de mandato; Fernando Collor de Melo 112, com média de 56; Itamar Franco 18, com média de nove; Fernando Henrique Cardoso 145, com média de 18; Luiz Inácio Lula da Silva homologou 79 terras, com média de dez; Dilma Rousseff, por fim, homologou, em 2011-2012, um total de dez terras, com média de cinco por ano. Ainda segundo o relatório mencionado, há 644 terras aguardando o início ou o término do processo de regularização fundiária.

7 As diretrizes norteadoras do processo administrativo de demarcação das terras indígenas estão definidas na Lei no 6.001, de 19/12/1973, e no Decreto n 1.775, de 08/01/1996. O rito legal inicia-se com a identificação e a demarcação da terra tradicionalmente ocupada por um grupo étnico, seguida da portaria declaratória do Ministério da Justiça. Daí segue-se a demarcação física propriamente dita, que dá ensejo à preparação documental necessária à homologação via decreto presidencial. O processo termina com o registro cartorial na comarca pertinente e na Secretaria de Patrimônio da União do Ministério da Fazenda. Todas as fases do processo são contestáveis judicialmente, o que pode arrastá-lo durante anos.

8 Nossa pesquisa de doutorado analisa os eixos analíticos da luta por reconhecimento, a judicialização de conflitos e as especificidades da arquitetura institucional brasileira em torno do sistema decisório acerca da demarcação de terras tradicionalmente ocupadas por povos indígenas. Ainda em seus passos iniciais, este trabalho apresenta-se como uma oportunidade ímpar para que possamos iniciar a articulação de conceitos atinentes ao campo de estudos dos movimentos sociais e nos debruçarmos sobre um estudo de caso concreto. 
entre 2009 e 2016, apresentando os principais ciclos de protesto do período, com foco especial para o ciclo compreendido entre junho de 2013 e dezembro de 2014.

Iniciaremosnosso debate apresentando uma breve discussão sobre o atual estágio do movimento social que aglutina as organizações que lutam pelos direitos dos povos tradicionais brasileiros. $\mathrm{Na}$ sequência, apresentamos o framework analítico já aludido, com ênfase nos conceitos de repertório de confronto e ciclo de protestos, o que nos fornecerá os elementos necessários para uma análise aqui proposta. Antes, porém, faremos uma breve digressão para aprofundarmos no teor da PEC 215/2000 e suas transformações e vicissitudes ao longo de seus 14 anos de tramitação, de modo a prover um quadro mais claro acerca da matéria objeto de conflito e dos atores políticos envolvidos.

Por fim, tomamos como fonte de dados os sites da Articulação dos Povos Indígenas do Brasil (APIB). Recorremos a essas plataformas virtuais de mobilização dos movimentos sociais indígenas porque elas nos proveem a possibilidade de fazermos um apanhado do repertório de ação utilizados por estes movimentos. ${ }^{9}$ Entre junho de 2013 e dezembro de 2014 há três importantes marcos temporais: o grande ato da Mobilização Nacional Indígena (realizada entre 30/09 a 05/10 de 2013), o Dia do Índio (19/04 de 2014) e a Marcha realizada em conjunto com o Comitê Popular da Copa do Mundo e outros movimentos sociais (27/05/2014). Este período de 18 meses será considerado, de acordo com o referencial teórico por nós utilizado, como um grande ciclo de protestos que encontram nestas datas mencionadas seus momentos de maior intensidade.

Concluímos este trabalho apontando as principais tendências observadas a partir dos dados fornecidos pelo próprio movimento

9 A busca pelo site dessa organização revela dois endereços: um, que é onde se encontra a descrição apresentada na sequência, cobre o período de 2009 a 2012 (<http://blogapib.blogspot.com.br/>); o segundo cobre o período de junho de 2013 até o mês de reação deste artigo (maio de 2016), e tem como título"Mobilização Nacional Indígena" (<https://mobilizacaonacionalindigena.wordpress. $\mathrm{com} />$ ). Neste trabalho, nos debruçamos sobre os dois sítios eletrônicos para caracterizamos de forma ampla o repertório de ação do movimento indígena brasileiro, mas, conforme vimos afirmando, dedicaremos especial atenção ao segundo destes por abranger o período de discussão sobre a já mencionada PEC 215. 
indígena no período analisado e tecemos algumas considerações sobre a relação desses protestos com a questão da demarcação territorial indígena no Brasil.

\section{Breve história do movimento social indígena brasileiro}

A colonização do continente americano foi marcada, desde seus primórdios, por um processo expansionista de exploração de seus bens naturais e escravização dos povos originários. Por meio da disseminação de doenças, expulsão e conquista de territórios habitados por povos indígenas diversos, imposição de línguas estrangeiras e concomitante proibição do uso das línguas próprias desses grupos, e, na maioria dos casos, extermínio físico direto destes, as potências coloniais europeias consolidaram sua dominação e reduziram os grupos étnicos autóctones a apenas uma fração de sua população anterior (Cunha, 2012). ${ }^{10}$

Historicamente desconsiderados como sujeitos de direitos, os povos indígenas contam, pelo menos a partir dos processos de redemocratização em curso na América Latina desde fins da década de 1980, com um sólido arcabouço legal que dá respaldo à sua luta para a manutenção de suas religiões, línguas, modi vivendi e terras por eles habitadas. A promulgação da Convenção 169 da Organização Internacional do Trabalho (OIT), em 1989, que dispõe sobre os povos indígenas e tribais em países independentes, e a Declaração das Nações Unidas sobre os Direitos dos Povos Indígenas são marcos jurídicos internacionais que dizem respeito aos princípios éticos, políticos, jurídicos e culturais a serem seguidos pelos países signatários destes tratados ${ }^{11}$ (OIT, 1989; ONU, 2008; Ramos, 2012).

10 Cunha (2012) demonstra que as estimativas variam enormemente tanto quanto no que se refere à população aborígene habitante no continente em 1492 quanto à depopulação ocorrida nos séculos seguintes. As estatísticas mais conservadoras falam em perda de um quarto da população original, enquanto outras afirmam que o percentual de indígenas exterminados chegaria à ordem de $95 \%$ de uma população entre 8 a 112 milhões de indivíduos. Em ambos os cenários, todavia, verifica-se a ocorrência de um genocídio de grandes proporções ocorrido no continente americano.

11 O Brasil ratificou a convenção em 2002. Lista disponível no site oficial da OIT: <www.lo.org>. Acesso em: 4 out. 2015. 
Trejo (2006) afirma que a América Latina vive hoje a "quarta onda de mobilizações étnicas", período marcado pelo ressurgimento de demandas de grupos indígenas específicos. ${ }^{12}$ Elencando um exaustivo rol de variáveis explicativas para este ressurgimento, o autor evidencia a importância decisiva do lastro territorial das identidades étnicas emergentes, o que torna a demarcação territorial indígena o principal móvel político das disputas contemporâneas destes grupos com outros segmentos da sociedade civil e com o Estado.

Neves (2006) traça um amplo panorama da mobilização indígena brasileira desde a década de 1970, com a realização das assembleias indígenas, até a década de 1990, marcada pela adesão ao projeto neoliberal em âmbito federal que esvaziou politicamente a Funai e enfraqueceu as articulações dos movimentos sociais. ${ }^{13}$ Marés (2003), por seu turno, abordando os casos das lutas pela demarcação das terras indígenas Xetá, Guarani e Pataxó Hãhãhãe, alude à tensão existente entre a figura da "terra indígena", marcadamente eurocêntrica, sujeita ao direito de propriedade fundante do direito ocidental, e a concepção de "território", entendido como um lastro simbólico para a construção de uma identidade indígena, um espaço coletivamente apropriado por uma determinada comunidade. Em suas palavras (Marés, 2003, p. 102), “[...] os direitos indígenas na América Latina sempre estão ligados a um espaço territorial, qualquer que seja o nome".

Seria impossível, em um trabalho deste escopo, proceder a um mapeamento das inúmeras organizações indígenas de caráter regional e nacional. Elegemos como de especial interesse para nós a APIB, por esta se configurar como uma espécie de "confederação" de movimentos sociais indígenas de todo o Brasil. Segundo informações constantes de seu site,

12 A primeira"onda" dataria do século XVI, nas primeiras rebeliões indígenas no momento imediatamente pós-conquista; a segunda, durante o regime dos Bourbons, na Espanha, no contexto das lutas pela independência da América Hispânica; a terceira, no século XIX/XX; e a quarta a partir da década de 1970 .

13 Para uma visão comparativa desse processo com o caso colombiano e o papel central do Cimi na organização política dos povos indígenas brasileiros, ver Ramos (2002). 
A Articulação dos Povos Indígenas do Brasil (APIB) é a instância nacional de deliberação e articulação política do movimento indígena. A entidade congrega as organizações indígenas regionais de todos (sic) o país. A APIB também possui uma Comissão Nacional Permenente (sic) (CNP) em Brasília formada por representantes das organizações e assessoria técnica (APIB, 2012).

Criada em 2009, a APIB aglutina os seguintes movimentos indígenas: Articulação dos Povos Indígenas da Região Sul (ARPINSUL); Articulação dos Povos Indígenas do Pantanal e Região (ARPIPAN); Coordenação das Organizações Indígenas da Amazônia Brasileira (COIAB); Articulação dos Povos Indígenas do Sudeste (ARPINSUDESTE); Aty Guasu (Grande Assembleia Guarani-Kaiowá); Articulação dos Povos e Organizações Indígenas do Nordeste, Minas Gerais e Espírito Santo (APOINME). Coordenada desde 2013 pela reconhecida liderança indígena de Sônia Guajajara, a organização tem se mostrado intensamente combativa, criando e articulando a chamada Mobilização Nacional Indígena, cujo objetivo foi o de demonstrar que "é hora de ir para cima, para o embate" 14 com a bancada ruralista no Congresso Nacional e as iniciativas do Poder Executivo que, na leitura destes movimentos, prejudicam os direitos adquiridos das populações indígenas tradicionais do Brasil.

Esses movimentos sociais organizados em torno da APIB lutam por quais motivos? Conforme anteriormente mencionado, o ciclo de protestos iniciado em junho de 2013 e findo em dezembro de 2014 teve como bandeira maior o impedimento da aprovação da PEC 215/2000. Para melhor entendermos o foco da mobilização, apresentaremos, na sequência, com mais detalhes, do que trata a referida peça legislativa.

14 Este é o título da entrevista de Sônia Guajajara à revista Carta Capital, em 28/09/13, disponível em: <http://www.cartacapital.com.br/politica/201ce-hora-de-ir-para-cima-para-o-embate201d-4865. html>. Acesso em: 2 jan. 2015. 


\section{O pomo da discórdia: a PEC 215/2000}

A PEC 215/2000, de autoria do então deputado Almir Sá (Partido Progressista Brasileiro em Roraima - PPB/RR), foi apresentada ao Plenário da Câmara dos Deputados no ano 2000. ${ }^{15}$ Ao longo de seus 14 anos de tramitação, essa polêmica peça legislativa foi relatada por três deputados diferentes, ${ }^{16}$ arquivada e desarquivada duas vezes, e ensejou a criação de uma Comissão Especial para sua análise detalhada. Não é nosso intuito descer, aqui, aos detalhes do projeto, tampouco mapear a enorme controvérsia por ele gerada, mas antes fornecer um quadro mais sucinto e esquemático das principais vicissitudes pelas quais ele passou ao longo de seu debate na Câmara dos Deputados.

A referida proposta visa acrescentar o inciso XVIII ao Art. 49 e modificar o $\$ 4^{\circ}$, além de acrescentar o $\$ 8^{\circ}$, ambos no Art. 231, da Constituição Federal. Conforme consta de sua ementa,

Inclui dentre as competências exclusivas do Congresso Nacional a aprovação de demarcação das terras tradicionalmente ocupadas pelos índios e a ratificação das demarcações já homologadas; estabelecendo que os critérios e procedimentos de demarcação serão regulamentados por lei (Brasil, 1988).

A justificação do projeto apresentada pelo deputado concentra-se em dois argumentos básicos: a) a demarcação de terras tradicionalmente ocupadas é uma ação do governo federal, cujas implicações para os estados podem ser "desastrosas", uma vez que, por vezes, implica a desapropriação de imóveis rurais alegadamente

15 Todos os dados aqui apresentados, assim como a íntegra dos documentos, áudios, requerimentos, votos e pareceres envolvidos na matéria aqui analisada podem ser encontrados no site da Câmara dos Deputados: <http://www2.camara.leg.br/atividade-legislativa/comissoes/comissoes-temporarias/ especiais/54a legislatura/pec-215-00-demarcacao-de-terras-indigenas >. Acesso em: 20 dez. 2014. Destacaremos nesta seção apenas os pontos que julgamos mais importantes, tendo em vista o recorte do presente trabalho.

16 Pela ordem, os deputados Luiz Couto (Partido dos Trabalhadores da Paraíba - PT/PB), Geraldo Pudim (Partido do Movimento Democrático Brasileiro do Rio de Janeiro - PMDB/RJ) e, finalmente, Osmar Serraglio (Partido do Movimento Democrático Brasileiro do Paraná - PMDB/PR). 
produtivos, afetando a economia regional. Desta forma, feriria o pacto federativo, posto que realizaria uma intervenção no território das Unidades da Federação sem consulta prévia à sua representação política no Senado ${ }^{17}$ b) esta ação é reconhecida como um processo administrativo levado a cabo pelo Ministério da Justiça e cuja homologação é consubstanciada por decreto presidencial. Desta forma, sua legitimidade estaria sempre passível de contestação no Supremo Tribunal Federal, o que geraria um indesejado quadro de insegurança jurídica. O projeto, portanto, visaria sanar estes dois problemas, ao transferir as competências de demarcação territorial para o Senado, que conferiria a legitimidade e o aval necessário dos estados, nos quais se dariam as demarcações que, por sua vez, seriam consolidadas em lei ordinária.

Um dos pontos mais polêmicos do projeto, posteriormente vetado pelos votos dos relatores da matéria, por ser considerada inconstitucional, previa a ratificação das demarcações já homologadas, ou seja, a revisão completa de todos os processos realizados após a promulgação da Constituição de 1988.

A seguir apresentamos um quadro esquemático do que julgamos serem marcos temporais importantes do processo de tramitação da PEC aqui em análise.

Quadro 1 - Apresentação esquemática da tramitação da PEC 215/2000

\begin{tabular}{c|c}
\hline Data & Evento \\
\hline 2000 & Apresentação da PEC 215, de autoria do deputado Almir Sá (PPB/RR) ao Plenário da Câmara. \\
\hline
\end{tabular}

17 A PEC apresenta um foco relevante no argumento "federalista", fazendo notar que os "impactos" decorrentes das demarcações territoriais são, por vezes, demasiado importantes para não levarem em conta a perspectiva dos governos estaduais. Cumpre notar que, de acordo com Scholtz (2006), ao analisar o caso das políticas indigenistas do Canadá, dos Estados Unidos da América, da Nova Zelândia e da Austrália, a variável "federalismo"é considerada como um elemento que tende a retardar ou mesmo inviabilizar os processos de reconhecimento territorial de territórios tradicionalmente ocupados. Isto se daria porque as pressões dos interesses econômicos locais resistem em considerar legítima a delimitação de terras indígenas em áreas muitas vezes já exploradas por fazendeiros e mineradores. Como podemos notar, a explicação proposta pela autora parece aplicar-se ao caso brasileiro sem a necessidade de mediações adicionais. 


\begin{tabular}{|c|c|}
\hline 2003 & $\begin{array}{l}\text { Início da tramitação da proposta na Comissão de Constituição, Justiça e Ci- } \\
\text { dadania, com relatoria do deputado Luiz Couto (PT/PB). }\end{array}$ \\
\hline 2005 & Apresentação do parecer do relator pela inadmissibilidade da matéria. \\
\hline 2007 & Arquivamento pela Mesa Diretora da Câmara; desarquivamento no mesmo ano e devolução ao relator. \\
\hline 2008 & $\begin{array}{l}\text { Designado novo relator, deputado Geraldo Pudim (PMDB/RJ); voto do relator pela inadmissibilidade da matéria } \\
\text { (junho); novo voto do relator, desta vez pela admissibilidade da matéria e propostas apensadas a ela (dezembro). }\end{array}$ \\
\hline 2011 & $\begin{array}{l}\text { Arquivamento da matéria pela Mesa Diretora da Câmara; desarquivamento no mesmo ano; } \\
\text { designado como novo relator o deputado Osmar Serraglio (PMDB/PR); primeiro requeri- } \\
\text { mento de audiência pública da parte do deputado Alessandro Molon (PT/RJ). }\end{array}$ \\
\hline 2012 & $\begin{array}{l}\text { Parecer aprovado pela comissão e publicado no Diário da Câmara; requerimento do deputado João Campos } \\
\text { (PSDB/GO) para o estabelecimento de Comissão Especial para debate da PEC 215/2000 e proposiçốes apensadas. }\end{array}$ \\
\hline 2013 & $\begin{array}{l}\text { Quatro requerimentos propondo a instalação da Comissão Especial; criação, mediante ato da Presidência da } \\
\text { Câmara, da Comissão Especial (GTTERRAS); requerimento de cinco audiências públicas para debater o tema. }\end{array}$ \\
\hline 2014 & $\begin{array}{l}\text { Apresentação de } 42 \text { requerimentos para a realização de audiências públicas, por parte de deputados de diversos } \\
\text { partidos; perda do prazo regimental para a votação da PEC e sua consequente extinção e arquivamento. }\end{array}$ \\
\hline
\end{tabular}

Fonte: Câmara dos Deputados do Brasil.

Elaboração própria.

Os protestos contra a PEC 215/2000 foram marcados por inúmeras estratégias e devem ser entendidos em um contexto mais amplo de mobilizações. Para que possamos ter uma visão mais clara sobre o quadro geral, faz-se necessária a delimitação de algumas balizas conceituais, como veremos a seguir.

\section{Políticas de protesto: mapeando alguns conceitos necessários ao debate}

Em nossa discussão, faz-se de suma importância a delimitação de dois conceitos oriundos da literatura acadêmica sobre movimentos sociais, sobretudo aquela que se debruça sobre a faceta contenciosa de suas lutas. Estes são: o conceito de repertório de ação e ciclo de protestos. Nas linhas seguintes apresentaremos, sem a pretensão de aprofundarmos demasiado, o debate, as linhas de força destes construtos teóricos, ferramentas conceituais que nos ajudarão a explicar o fenômeno aqui em estudo.

Seguindo a apresentação de Sidney Tarrow (2009, p. 51), é necessário que iniciemos conceituando repertório de ação 
coletiva, assim como definido por Charles Tilly, ou seja, como "as maneiras através das quais as pessoas agem juntas e buscam objetivos compartilhados". A um só tempo cultural e estrutural - e, seria forçoso acrescentar, relacional -, o conceito também abarca o conhecimento que os indivíduos têm sobre suas formas de realizar os protestos, e, além disso, a expectativa social sobre suas ações.

Refinando o conceito, os autores propõem a bifurcação entre dois tipos de repertórios, quais sejam, um repertório "tradicional", marca das agitações em comunidades europeias no século XVIII e XIX, e um repertório "moderno" ou modular. O primeiro, segundo as linhas estabelecidas por Tilly e endossadas por Tarrow, definirse-ia por um caráter estreito - o que significa estarem, no mais das vezes, confinadas a uma comunidade -, bifurcado - oscilando entre a ação direta para atingir objetivos locais ou a apresentação de demandas a um patrono ou autoridade local, para que as levasse a um nível de governo nacional - e particular - ou seja, adquiria matizes comportamentais muito específicas, o que impedia seu traslado para outros contextos reivindicatórios. Seriam exemplos, neste sentido, os ataques a celeiros em tempos de carestia, incêndios a plantações e ocupação de fazendas, entre outros.

O segundo tipo, por sua vez, caracterizar-se-ia por mostrar-se intensamente cosmopolita - pois afetaria muitas comunidades de uma só vez, além de apresentar o cenário urbano das grandes metrópoles como cenário privilegiado das lutas dos movimentos sociais -, modular - talvez sua característica mais pronunciada, ou seja, são facilmente transplantadas para serem utilizadas em outros contextos - e autônomo - no sentido de ser fruto de iniciativa de cidadãos almejando contato direto com os centros-alvo de poder de suas demandas, sem a necessidade de intermediários. Comícios, reuniões públicas, barricadas, petições e greves são apenas alguns dos exemplos deste tipo de repertório.

É importante enfatizar aqui que o conceito, em que pese sua baixa precisão, quer dar relevo à potencialidade de generalidade - critério distintivo mais saliente entre os dois tipos de repertório propostos - presente em um conjunto de ações realizadas por um conjunto 
de indivíduos em situação de apresentação de demandas em um contexto de mobilização social. Não há repertório dado a priori ou imutável ao longo do tempo, sendo possível a utilização, por parte dos movimentos sociais, de uma ampla gama destas ações, o que dependeria somente da avaliação estratégica destes, do contexto de atuação e dos recursos disponíveis para tais escolhas.

Conceito que se tornou referência nos estudos sobre movimentos sociais na contemporaneidade, a noção de repertório foi reiterada, vezes criticada, por seu caráter demasiado estruturalista, pouco atento à conexão das formas de agir com o conjunto de emoções, sentimentos, ideias e simbolismos que necessariamente circundam as ações coletivas de caráter confrontacional. Ademais, como nota Bringel (2012), além deste viés ontológico aludido, há ainda sérias implicações epistemológicas e metodológicas do conceito que devem ser questionadas no sentido de torná-lo uma ferramenta mais precisa para abarcar os fenômenos que pretende descrever. $\mathrm{O}$ próprio Charles Tilly, em sua obra tardia, incorporou essas críticas ao conceito, passando a entendê-lo como conjuntos de performances complexas adaptadas pelos atores sociais em contextos específicos de luta (Alonso, 2012).

Alonso (2012, p. 32) descreve o refinamento do conceito na obra de Tilly com a bela metáfora sobre a passagem de um olhar de "botânico das formas de protesto" para o de um músico "atento aos improvisos" emergentes nos processos de mobilização coletiva de caráter contencioso. É importante ressaltar, todavia, que, no que tange ao movimento indígena brasileiro, a pesquisa ainda se apresenta em seu estágio "botânico", devido à necessidade imperiosa de darmos um passo inicial rumo a níveis mais complexos de produção de conhecimento sobre ele. Afinal de contas, como esta autora reconhece (Ibid., p. 34), "o conceito de repertório, como todos os tillyanos, não é fórmula a ser aplicada a qualquer circunstância; é convite à pesquisa empírica de contextos históricos particulares".

O segundo conceito que se reveste de importância superlativa para nós é o de ciclo de confronto. Ainda segundo Tarrow (2009, p. 182), pode-se entender este conceito como "fase de conflito acentuado 
que atravessa um sistema social", durante o qual se verifica um ritmo acelerado na produção de inovações em termos de repertório de confronto, os movimentos sociais conseguem o envolvimento de cidadãos não militantes, produzem ou combinam distintos quadros interpretativos e desafiam as autoridades constituídas. Passam por uma fase de intensa mobilização, seguida de um "pico" no qual se verifica o momento de maior tensão entre os desafiantes e os representantes governamentais, e, posteriormente, sua fase de desmobilização.

A literatura recente sobre movimentos sociais brasileiros tem trabalhado com esse conceito. Tatagiba (2014), por exemplo, discute três grandes ciclos de protesto na história recente brasileira, quais sejam, aquele em torno da campanha Diretas Já, em 1984; o ciclo que culminou com o impeachment do então presidente Fernando Collor de Melo; e, mais recentemente, os protestos de junho de 2013. Rodrigues (2001), por seu turno, discute o que chamou de grandes ciclos de mobilização política de entrada e saída do governo militar em 1964 e 1984, respectivamente. Em comum nestes trabalhos está a ênfase na ideia de alastramento de ações coletivas contenciosas de uma escala local para uma escala nacional como um fator decisivo para distinguir o conceito de termos correlatos que descreveriam situações de menor intensidade e escopo, tais como a ideia de ciclos de mobilização.

Entendemos que essa aplicação do conceito a processos de larga escala é interessante porque provê insights valiosos para a compreensão da dinâmica nacional em alguns de seus momentos decisivos. No entanto, apresenta-se como inescapável, nesse tipo de desenho de pesquisa, o problema da causalidade remota, ou seja, a impossibilidade de declarações causais mais fortes sobre quaisquer que sejam os fatores explicativos elencados para o desencadeamento destes grandes ciclos de protesto. Neste sentido, na contramão da tendência a abordar fenômenos de grande amplitude, este artigo está focando em um ciclo muito mais modesto em escopo, com vistas a promover um olhar mais atento para dinâmicas não necessariamente espraiadas por todo o território nacional. 
Em nosso breve panorama conceitual, optamos por nos centrar na ideia de "fase de conflito acentuado", que se refere ao núcleo "duro" do conceito, por entendermos que a demonstração pormenorizada dos demais elementos definidores deste demandariam um trabalho de maior fôlego do que o aqui apresentado. ${ }^{18}$ Decisivo para nós aqui é, no entanto, a noção de que os movimentos sociais indígenas brasileiros embarcaram em um ciclo de confronto, com vistas a bloquear a tramitação e a aprovação da PEC 215/2000, que se estende desde abril de 2013, com a ocupação do Plenário da Câmara, até dezembro de 2014, quando o prazo-limite de prorrogação para a aprovação da matéria exauriu-se, e esta foi arquivada. Este ciclo, por sua vez, apresenta "picos", conforme veremos na próxima seção deste trabalho.

Cabe salientar que estamos sempre nos movendo em um contexto político em que os movimentos sociais estão apresentando suas demandas ao Estado. Em outras palavras, temos que ressaltar, conforme Tarrow (2012), a importância do sistema político institucional como player decisivo e indispensável para o entendimento dos fenômenos aqui apresentados. É sobretudo a deficiência estatal - em seus níveis regional e central - de prover às populações indígenas serviços públicos básicos e reconhecimento de seus direitos de ocupação das terras tradicionais que agiu como disparadora das mobilizações aqui analisadas.

Pensar a complexa relação entre movimento social indígena e Estado brasileiro está além dos limites deste trabalho. No entanto, é forçoso reconhecer que a seminal discussão empreendida por Goldstone (2003) sobre o continuum de táticas confrontacionais

18 O conceito é, de fato, "escorregadio", e permite brechas para algumas definições ad hoc, tais como, por exemplo, a duração do ciclo e quais atores serão considerados partícipes deste. O caso em tela neste artigo é exemplar. Com relação à duração do ciclo de protesto aqui analisado com mais vagar, tomamos como baliza temporal aquele indicado pelo próprio movimento indígena. Da mesma forma, estamos analisando a questão sempre do ponto de vista de uma organização - no caso, a APIB, escolhida justamente por ser composta por indígenas, deixando de lado atores importantes, tais como o já citado Cimi e o Instituto Socioambiental (ISA), duas organizações não governamentais com relevante atuação na política indígena nacional. Estas escolhas compõem uma narrativa que, certamente, poderia ganhar outros contornos a partir da inclusão de outros elementos na análise, às expensas, no entanto, da objetividade e do escopo de um trabalho desta natureza. Agradecemos ao professor Marcus Abílio Gomes Pereira por nos chamar a atenção para este ponto. 
e formas tradicionais de interação política entre atores coletivos e poder estatal pode ser uma chave analítica interessante para se pensar o conjunto heterogêneo de táticas utilizadas pelo movimento social indígena brasileiro, conforme veremos a seguir. A ideia de que opor em polos irreconciliáveis movimentos sociais e atores estatais é uma forma errônea de conceber esta relação foi recentemente trabalhada por Abers, Serafim e Tatagiba (2014) a partir de estudos de casos em diferentes políticas públicas de âmbito federal, demonstrando que captar as alianças e demais estratégias de proximidade entre estes faz-se necessário para compreender, de forma mais acurada, certos resultados políticos e institucionais. Portanto, esse enquadramento conceitual pode apresentar-se como especialmente profícuo, ao tornar-se um importante complexificador dos fenômenos em tela neste estudo.

Por fim, é forçoso recordar que o ponto-chave das mobilizações indígenas brasileiras nos últimos anos é a luta pelo reconhecimento dos territórios tradicionais, encabeçada pelas organizações indígenas que emergem na condição de interlocutores legítimos das demandas destes grupos perante outros grupos sociais e ao Estado. Conforme sintetiza León Trujilo (1991, p. 389 apud Neves, 2006, p. 122), uma vez reconhecidas pelo Estado, "[...] as organizações indígenas convertem-se em representantes de coletividades ou de povos, um fenômeno recente, que se consolida com a produção de discursos étnicos, formação de pessoal e de formulação de projetos próprios". Neste sentido, vale a pena buscar conhecer, de forma empírica, como as organizações indígenas brasileiras têm se organizado para apresentarem-se como propositores de "ameaças críveis" perante os demais atores governamentais brasileiros (Scholtz, 2006).

Delimitadas nossas balizas conceituais, apresentaremos, na sequência deste trabalho, os resultados de nossa incursão empírica aos sites da APIB. Nosso intuito é utilizar os conceitos anteriormente elencados para a análise do caso concreto de uma mobilização do movimento social indígena, iniciada a partir de junho de 2013, e encontrando seu termo ao fim de 2014. Nossa coleta de dados, no entanto, abrange o período de 2009 a 2016, apresentando a 
mobilização aqui em tela como um caso imerso em um padrão mais amplo de repertórios de ação e de mobilizações realizadas nos últimos anos no Brasil.

\section{Como protesta o movimento social indígena brasileiro? Uma primeira incursão empírica}

Uma vez delineados os conceitos centrais de nosso trabalho, voltemo-nos para o caso concreto por nós eleito para fornecer-nos um primeiro panorama sobre as atividades de mobilização indígena no país, focando as atividades que fazem parte de seu repertório de ação.

Nossa incursão aos dois sites da APIB revelou-nos a existência de plataformas virtuais que aglutinam uma série de informações importantes para os movimentos sociais e eventuais pesquisadores vinculados ao tema. Com interface simples e poucos recursos de mídia, os blogs mostram-se de fácil entendimento e acesso. Consultamos os arquivos de todos os meses disponíveis nos dois sites, ou seja, de março de 2009 a março de 2016. Fizemos um apanhado de todas as notícias relativas a mobilizações indígenas apresentadas, selecionando aquelas que se referiam especificamente a atos, marchas, reuniões, protestos, entre outras formas de ação coletiva. A partir destas notícias nós buscamos identificar: a) o mês/ ano em que a ação ocorreu; b) o tipo de ação empreendida; c) a cidade e o estado da ação; d) a(s) etnia(s) envolvida(s) na ação.

Tendo em vista nosso referencial teórico, buscamos categorizar as ações relatadas nas postagens, chegando às dispostas a seguir:

- Caminhadas/marchas/passeatas: esta categoria englobou todas as atividades de deslocamento de contingentes de participantes ao longo de estradas/ruas/avenidas, com vistas à demonstração de faixas e cartazes, cânticos, hinos e congêneres;

- Ocupação de instituições pública/espaços públicos: compreendeu todas as atividades de ocupação pacífica ou violenta de instituições públicas federais, estaduais ou 
municipais, assim como de espaços públicos ao ar livre, como praças e logradouros;

- Ocupação de propriedades privadas: abarcou todas as ocupações pacíficas ou violentas de fazendas ou instituições de caráter privado;

- Ativismo midiático/digital: diz respeito a convocatórias on-line para "twittaços", divulgação em redes sociais, vídeos de convocação para marchas, divulgação de cartas públicas e manifestos apresentados primeiramente na internet, participação de coletivas de imprensa;

- Bloqueios de estradas: as atividades de impedimento da livre circulação de veículos e indivíduos em determinadas rodovias estaduais, federais ou municipais;

- Atos simbólicos: acampamentos, cânticos, apresentação de faixas e cartazes, participação em audiências públicas, eventos internacionais, apresentação de denúncias a órgãos judiciários nacionais e entidades internacionais, reuniões com autoridades públicas.

Foram caracterizadas como "multiétnicas" aquelas ações que contaram com a presença de dois ou mais grupos étnicos em seu desenvolvimento, ao passo em que as ações realizadas por apenas um grupo étnico foram denominadas com o próprio nome do grupo.

Para o período entre março de 2009 e março de 2016 foram contabilizadas 286 ações de protesto do movimento indígena brasileiro em 19 estados brasileiros e no Distrito Federal, além de ações no âmbito internacional (Estados Unidos da América, Inglaterra, África do Sul e alguns países europeus). No ano de 2009 foram anotadas 44 ações; em 2010, 43; em 2011, 82, o maior indicador para o intervalo analisado; em 2012, 34; 2013 contou com 35 ações; 2014 presenciou 19 ações; 2015, 26; e, por fim, 2016, com três ações até março daquele ano. O gráfico 1 demonstra a distribuição das ações no período analisado. 
Gráfico 1 - Distribuição anual das ações do movimento indígena entre 2009 e 2016

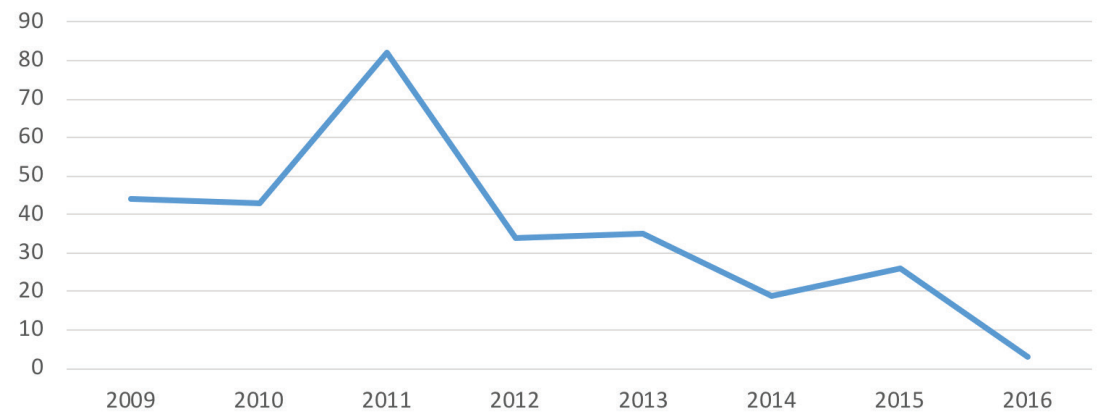

Fonte: APIB.

Elaboração própria.

No período em destaque identificamos, em uma lista não exaustiva, alguns marcos importantes para o movimento indígena brasileiro, quais sejam: a) a expedição da licença para a construção das obras da Usina Hidrelétrica de Belo Monte em outubro de 2009; b) o rompimento formal do diálogo entre as lideranças indígenas e o governo federal em junho de 2011, com sua retomada em agosto do mesmo ano; c) a ocupação do canteiro de obras de Belo Monte em outubro de 2011; d) a morte do cacique Nísio Gomes no contexto de disputas fundiárias em Mato Grosso do Sul em novembro de 2011; e) destaque nacional e internacional para a divulgação de uma suposta carta de "suicídio coletivo" do povo Guarani-Kaiowá naquele estado em 2012; f) Mobilização Nacional Indígena iniciada em 2013 e confrontos com a polícia no Distrito Federal em 2014. Além disso, do ponto de vista da conjuntura nacional, é relevante relembrar que, em junho de 2013, ocorreram os eventos de manifestação de massa em milhares de cidades brasileiras, que ficaram conhecidos como Jornadas de Junho. Isto quer dizer que o período de mobilização aqui em foco deslancha logo após as maiores manifestações de rua já presenciadas no Brasil em sua história, em um contexto de grande tensão social. ${ }^{19}$

19 O significado dos eventos de junho de 2013 está aberto ao debate e ainda assim permanecerá, em nossa avaliação, durante muito tempo. Há algumas tentativas de conferir inteligibilidade aos acontecimentos (Avritzer, 2013; 2016; Alonso e Mische, 2016; Tatagiba, 2014), mas consideramos que ainda não há um estudo sistemático e aprofundado sobre as causas e as consequências destes para o sistema político brasileiro. 
Como se observa, o ano de 2011 foi o de maior intensidade das ações de protesto do movimento indígena no período observado, em que pese a não disponibilidade de dados para o ano de 2016 de forma completa. Não obstante, pode-se considerar que, de forma geral, o número de atividades do movimento apresenta uma trajetória descendente desde 2012, apresentando apenas uma pequena reversão desta tendência entre 2014 e 2015.

Essas atividades distribuíram-se em diversas regiões do país, apresentando: 30 atividades realizadas em Mato Grosso do Sul; 26 no estado do Amazonas; 14 no estado do Pará; oito em Santa Catarina; seis nos estados do Rio Grande do Sul e do Paraná; cinco em São Paulo e na Bahia; quatro em Roraima; três em Mato Grosso, no Tocantins, em Minas Gerais, no Rio de Janeiro, em Pernambuco, no Maranhão e no Ceará; e, por fim, uma atividade registrada na Paraíba, em Alagoas e em Goiás. Em 19 das atividades registradas não foi possível identificar o estado de sua realização (denominadas "NI"). Seis atividades foram realizadas fora do país (denominadas "INT"). O grande foco das ações de protesto do movimento indígena concentrou-se, no entanto, em Brasília, com a expressiva marca de 139 ações. Esta distribuição de ações por estado no período analisado pode ser vista no gráfico 2 .

Gráfico 2 - Distribuição das ações do movimento indígena brasileiro nos estados e Distrito Federal

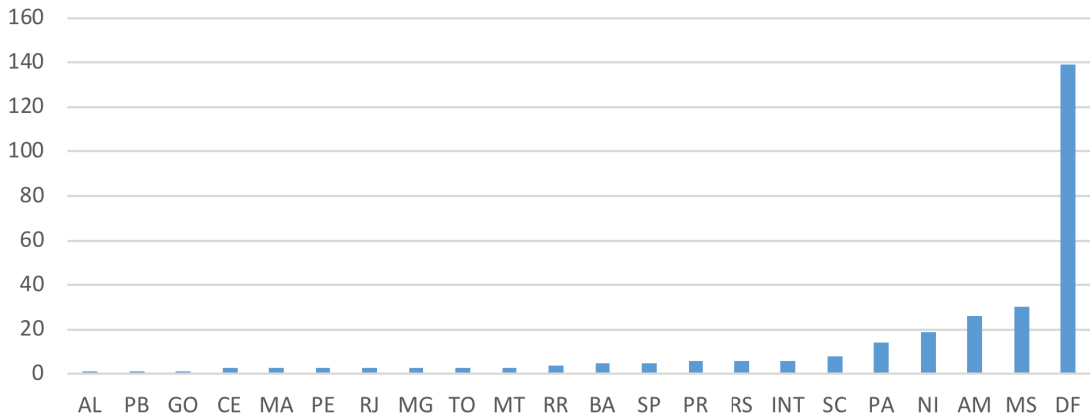


No que se refere aos atores empreendedores das ações de protesto do movimento indígena, identificamos um padrão fortemente pautado por um caráter "multiétnico", ou seja, as ações contaram, em 223 oportunidades, com a presença de dois ou mais grupos étnicos. Em termos de capacidade de mobilização individual destes grupos, identificamos: 13 ações realizadas pelos GuaraniKaiowá e nove pelos Guarani; seis pelos Kaingang e Terena; três por parte dos Ianomâmis; duas pelos Kayapó, Munduruku, Tapeba, Pataxó, Tupinambá e Xakriabá; uma levada pelos Tukano, Xavante, Xokleng, Xukuru, Potiguara, Oriximiná, Kapinawá e Gamela. Em seis oportunidades não foi possível identificar o grupo promotor da ação.

Voltando-nos para nossa categorização de ações que compõem o repertório de ação do movimento indígena brasileiro no período em análise, verifica-se uma forte prevalência de performances não contenciosas e de baixo custo organizacional: por um lado, 149 destas ações foram elencadas como fazendo parte da categoria "ativismo midiático/digital", além de 87 “atos simbólicos”. Por outro lado, ações que envolvem algum grau de conflito foram pouco utilizadas: sete ações de caminhadas e marchas; nove ocupações de propriedades privadas, especialmente de fazendas e apreensão de equipamentos; 15 bloqueios de estradas; e, finalmente, 15 ocupações de espaços e instituições públicas. O gráfico 3 apresenta este padrão. 
Gráfico 3 - Número de ações por categoria

MÍDIA E ATIVISMO DIGITAL

ATOS SIMBÓLICOS

OCUPAÇÃO DE INSTITUIÇÕES/ ESPAÇOS PÚBLICOS

BLOQUEIOS DE ESTRADAS

OCUPAÇÃO DE PROPRIEDADES PRIVADAS

CAMINHADAS/MARCHAS/PROTESTOS

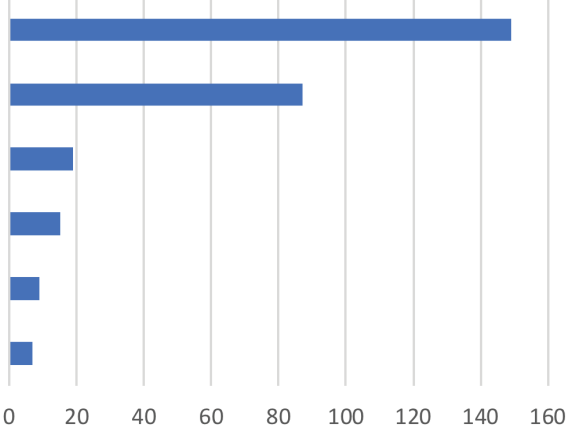

Fonte: APIB.

Elaboração própria.

Por fim, ressalte-se que esse repertório de ação variou conforme os anos, mostrando que o repertório composto por ações não conflitivas predominou durante todo o período aqui tratado, como se depreende do gráfico 4.

Gráfico 4 - Número de ações por categoria entre 2009 e 2016

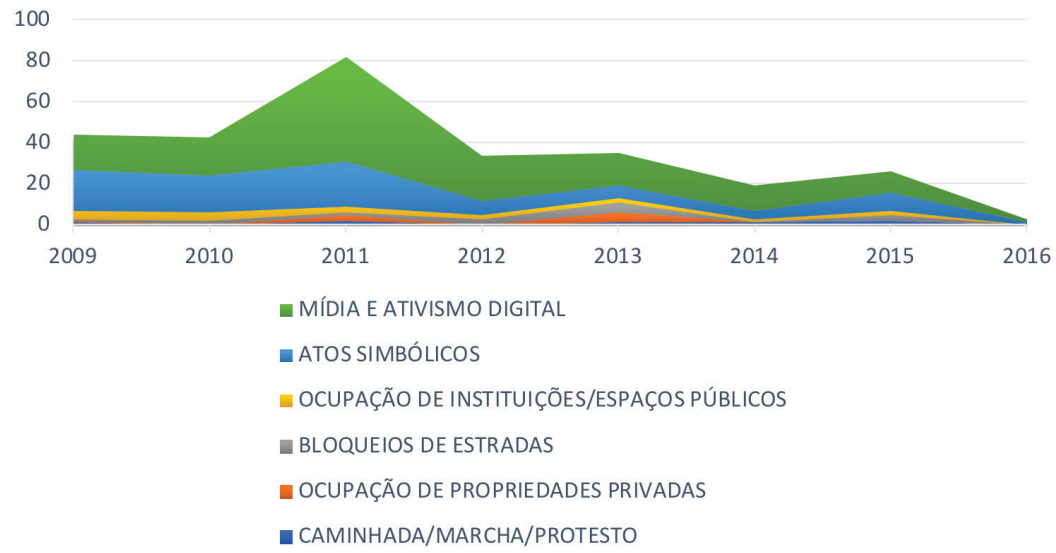

Fonte: APIB.

Elaboração própria. 
Podemos concluir, portanto, que o padrão de ações do movimento indígena brasileiro entre 2009 e 2016 é fortemente multiétnico e concentrado em Brasília, lançando mão de ações com forte apelo simbólico e amparadas na relação com mídias jornalísticas e digitais. Nos termos de Tarrow aqui discutidos, utilizam um repertório de ação coletiva marcadamente cosmopolita, modular e autônomo. Observa-se, a partir dos dados, um movimento social que lança mão de ações pouco conflituosas, optando por uma pauta de diálogo com os representantes do governo brasileiro. ${ }^{20}$

Ocupemo-nos, doravante, com o período da Mobilização Nacional Indígena que se inicia em 2013 e finda em 2014, foco principal deste trabalho. A tabela 1 traz o quantitativo dessas performances, realizadas nos estados de São Paulo, da Bahia, de Roraima, de Mato Grosso do Sul, de Goiás, do Maranhão, de Pernambuco, do Pará e no Distrito Federal.

Tabela 1 - Repertório de ação do movimento indígena entre agosto de 2013 e dezembro de 2014

\begin{tabular}{c|c|c|c|c|c}
\hline $\begin{array}{c}\text { Caminhada/ } \\
\text { marcha/passeata }\end{array}$ & $\begin{array}{c}\text { 0cupação de ins- } \\
\text { tituições públicas/ } \\
\text { espaços públicos }\end{array}$ & $\begin{array}{c}\text { Ocupação de pro- } \\
\text { priedades privadas }\end{array}$ & $\begin{array}{c}\text { Ativismo midiático/ } \\
\text { digital }\end{array}$ & Bloqueio de estradas & Atos simbólicos \\
\hline 2 & 4 & 5 & 28 & 5 & 10 \\
\hline
\end{tabular}

Fonte: APIB.

Elaboração própria.

O total de 54 atividades ao longo de 18 meses suscita algumas reflexões interessantes. Com menor frequência estão as atividades de marchas e passeatas, seguidas da ocupação de instituições

20 Esse é o tema de outro paper que estamos desenvolvendo no momento, a saber, a opção do movimento social indígena brasileiro por ações que primam pela ação comunicativa com os agentes do Estado brasileiro por meio da participação em audiências públicas, comissões parlamentares, reuniões com oficiais do alto escalão e participação em mecanismos de deliberação sobre a política indigenista brasileira. O que podemos afirmar até o momento é que, ao contrário do que poderia se imaginar a partir de um olhar mais superficial, não se trata de afirmar que o governo brasileiro"não conversa" com o movimento indígena, mas, antes, de verificar a aparente ineficácia de todos estes momentos de encontros entre os representantes indígenas e os representantes governamentais. 
ou espaços públicos e de propriedades privadas, e o bloqueio de estradas, em contraponto às atividades de ativismo digital e midiático e à realização de atos simbólicos de diversos tipos.

As marchas e passeatas, assim como a ocupação de espaços públicos, têm o condão de atrair a atenção da opinião pública para as pautas de reivindicação. As primeiras, segundo as estimativas colhidas no site, reuniram pelo menos 1.500 participantes. Este número é impreciso, uma vez que estas marchas são por vezes integradas por participantes de outros movimentos sociais, o que aumenta a incerteza sobre o número real de pessoas presentes no ato.

As ocupações dos espaços públicos, por sua vez, podem ser realizadas por um grupo menor de indivíduos (não foi possível quantificar o número de participantes em todos os atos), uma vez que usualmente se destinam a pressionar determinado gestor público para a realização de uma reunião ou audiência com representantes indígenas. Não foram registradas ações violentas de forças policiais nessas atividades.

De igual forma, não foram registrados confrontos entre indígenas e forças de segurança nas atividades de ocupação de propriedades privadas, muito embora fossem relatadas situações tensas. Destaque-se, nesta categoria, a ocupação da Confederação da Agricultura e da Pecuária do Brasil (CNA) - grande articuladora dos interesses do agronegócio no país e patrocinadora da PEC 215/2000, por cerca de 1.000 participantes, também sem registro de eventos violentos.

O bloqueio de estradas, por sua vez, configurou-se como uma atividade pouco recorrentenesseperíodo, contando com a participação de pelo menos 8.200 participantes em diversas localidades do país. Em que pese sua pouca utilização, essa ação tem grande impacto político, uma vez que bloqueia por horas ou mesmo dias a circulação de veículos, dando ensejo a grande prejuízo econômico.

Os atos simbólicos, categoria por nós criada para abarcar uma série de atos heterogêneos, foram parte importante do repertório de atuação do movimento social indígena. Muitas vezes valendo-se de pinturas corporais típicas, entoando cânticos e realizando danças rituais, demonstrando cartazes, os movimentos sociais lograram 
êxito em se fazerem presentes em audiências públicas (ou, como em um caso, recusando-se a participar sob a alegação de que, caso o fizessem, estariam legitimando os membros ruralistas que porventura estivessem presente) e em atividades em Assembleias Legislativas estaduais. Também se mobilizaram junto a fóruns internacionais, destacando-se a realização de protestos solidários em outros países e até mesmo a denúncia do governo brasileiro em sessão da Organização das Nações Unidas (ONU).

Por fim, o maior número de atividades do movimento indígena brasileiro entre agosto de 2013 e dezembro de 2014 foi relacionado ao ativismo digital e midiático. A participação em coletivas de imprensa e sobretudo a intensa utilização de vídeos com lideranças indígenas reconhecidas nacionalmente foram decisivas para dar coesão e capacidade mobilizadora aos movimentos sociais. Neste sentido, a produção de notas divulgadas à imprensa ou entregues diretamente às autoridades competentes foram ferramentas importantes para a produção de visibilidade da pauta indígena.

Por último, mas não menos importante, vale a pena observarmos o gráfico do número de ações do repertório de confronto aqui analisado por cada mês ao longo do período de 18 meses.

Gráfico 5 - Número de ações mensais entre agosto de 2013 e dezembro de 2014

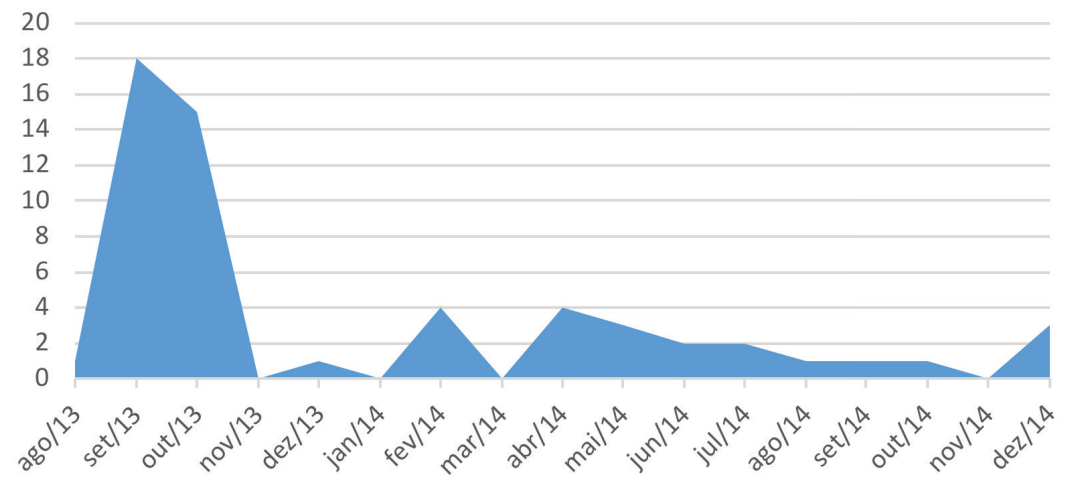

Fonte: APIB.

Elaboração própria. 
Percebe-se, a partir do gráfico 5, que as datas por nós compreendidas entre agosto de 2013 e dezembro de 2014 - o grande ato da Mobilização Nacional Indígena (realizada entre 30/09 e 05/10/2013), o Dia do Índio (19/04/2014) e a marcha realizada em conjunto com o Comitê Popular da Copa do Mundo e outros movimentos sociais (27/05/2014) - mostraram-se como pontos altos dos momentos de mobilização. Destaca-se também alguma intensidade de atividade dos movimentos nos meses que antecederam o período eleitoral em outubro.

Segundo pudemos observar, a APIB tem se mostrado como um valioso catalisador de diversas mobilizações dos grupos indígenas brasileiros em ações regionais e nacionais. Impressiona não somente o grande número de atividades realizadas ao longo de um considerável período, mas também a amplitude do repertório de atuação destes movimentos, que lançam mão desde ações de protesto clássicas, tais como o bloqueio de estrada e a ocupação de prédios públicos, até aquelas mais contemporâneas, tais como a difusão de vídeos em redes sociais e "twittaços" em ambiente virtual.

Vimos que o padrão de ações do movimento indígena entre agosto de 2013 e dezembro de 2014 segue o padrão geral das ações do movimento quando analisadas em um período maior de tempo, ou seja, são fortemente concentradas em Brasília e lançam mão de expedientes eminentemente não contenciosos. Há uma concentração evidente de ações no período entre agosto e outubro de 2013, precisamente quando a PEC 215/2000 parecia ganhar força renovada em sua tramitação, com a instalação de uma Comissão Especial para discutir seus pormenores.

\section{Considerações finais}

Nosso trabalho buscou realizar uma primeira incursão no tema dos movimentos sociais indígenas brasileiros, assentando sua análise a partir de dois conceitos oriundos do campo da teoria dos movimentos sociais, a saber, as ideias de repertório de ação e ciclos de protesto. Elegemos os sites da APIB como uma plataforma que 
poderia nos aportar dados interessantes para um mapeamento inicial das estratégias utilizadas pelos movimentos sociais indígenas ao longo de sete anos. Dentro deste panorama amplo, recortamos o caso da Mobilização Nacional Indígena contra a tramitação da PEC 215/2000, entre agosto de 2013 e dezembro de 2014, como um exemplo de um ciclo de protestos de especial relevância.

Nossos achados, ainda eminentemente descritivos, sugerem uma caracterização do movimento social indígena como empreendedor de uma ampla gama de ações clássicas e contemporâneas para a consecução de seus objetivos. Como vimos, a grande aposta do movimento é em atividades tais como participação em reuniões, produção de notas e divulgação para a imprensa, denúncias a órgãos competentes nacionais e internacionais, produção e divulgação de vídeos, campanhas virtuais, coletivas de imprensa, entre outras ações que poderíamos denominar de "dialógicas", no sentido de que se apresentam como ações mais baseadas na comunicação entre os atores sociais do que em ações de confronto. Correspondentemente, a maioria das ações dá-se na capital do país, o centro da Administração Pública Federal e dos demais poderes. Como podemos notar, para citarmos Warren e Jackson (2002, p. 9), "seria um erro congelar os grupos em fórmulas convencionais de essencialismo ou ativismo". ${ }^{21}$ Este achado, portanto, sugere a pertinência da ideia de continuum entre diferentes formas de ação dos movimentos sociais em relação aos atores estatais proposta por Goldstone (2003), uma vez que a conjugação entre repertórios contenciosos e não contenciosos por parte dos povos indígenas pode ter o condão de angariar mais interlocutores no âmbito dos poderes estatais (Alcantara, 2013).

Nesse sentido, talvez caiba refletir sobre a efetividade simbólica do uso desse repertório de ação. Em que pese a dificuldade de estabelecimento de uma relação causal entre as ações e os resultados práticos sobre a tramitação da PEC 215/2000, é preciso investigar de forma mais aprofundada sobre as possíveis formas de influência no

21 No original, "it would be a mistake to freeze groups in formulaic sorts of essentialism or activism". 
processo legislativo. Ao fim de 2014, a peça jurídica foi arquivada, apenas para ser desarquivada novamente em fevereiro de 2015, tendo uma longa tramitação ao longo deste ano. No presente momento, encontra-se parada na Coordenações de Comissões Permanentes para a publicação de seu último parecer, favorável ao seu encaminhamento para votação em Plenário. O questionamento, portanto, impõe-se: o movimento indígena brasileirotem conseguido impedir, momentaneamente, a aprovação desta legislação lesiva de seus direitos. Será, no entanto, capaz de continuar a fazê-lo mesmo no contexto de uma forte atuação da bancada ruralista no Congresso Nacional?

Do ponto de vista teórico, ainda remanescem muitas questões: os canais de diálogo entre o governo e o movimento indígena brasileiro, tais como a realização da recente $1^{\text {a }}$ Conferência Nacional de Política Indigenista e a instalação do Conselho Nacional de Política Indígena podem ser modelos institucionais efetivos para o encaminhamento de suas demandas? Como poderíamos refinar nossa categorização das ações? Em termos metodológicos, como poderíamos produzir uma mensuração mais precisa das ações de protesto no país?

Não obstante estarmos cônscios de que nosso estudo apresenta ainda muitas fraquezas do ponto de vista teórico e metodológico, acreditamos ter realizado um voo panorâmico sobre o tema a partir de alguns dados, que certamente também podem ser melhor completados se utilizadas outras fontes de consulta. Os fatores que levaram aos protestos analisados neste trabalho aparentemente continuaram no segundo governo Dilma, sobretudo após a nomeação da senadora Kátia Abreu (Partido do Movimento Democrático do Tocantins - PMDB/TO) para ministra da Agricultura e Pecuária. Notável defensora dos interesses dos grandes produtores rurais vinculados à Confederação Nacional da Agricultura, a então ministra manifestara-se de forma polêmica sobre o assunto da demarcação de territórios tradicionalmente ocupados por grupos indígenas, afirmando que os conflitos fundiários com estes grupos ocorrem porque "eles saíram da floresta e desceram sobre áreas 
produtivas". 22 A APIB divulgou carta em que lançava a pergunta sobre se o discurso "anti-indígena" seria a marca da política indigenista do segundo governo Dilma Rousseff. ${ }^{23}$ As evidências neste sentido foram abundantes antes da abreviação de seu mandato. ${ }^{24}$

O cenário pós-impeachment de Dilma Rousseff agravou esse cenário. A nomeação de Alexandre de Moraes para o Ministério da Justiça do governo Temer trouxe consigo propostas de modificação na legislação relativa ao processo de demarcação territorial indígena, visando torná-lo ainda mais restritivo. ${ }^{25} \mathrm{Na}$ sequência, Osmar Serraglio, membro histórico da bancada ruralista e relator da PEC 215, foi nomeado para a mesma pasta, com declarações igualmente indicativas do desinteresse político de avançar em pautas referentes aos povos indígenas. ${ }^{26} \mathrm{Na}$ culminância deste processo de desmonte da política indigenista brasileira, 347 servidores da Funai foram dispensados, agravando ainda mais sua crônica precarização

22 Disponível em:<http://www1.folha.uol.com.br/poder/2015/01/1570557-nao-existe-mais-latifundiono-brasil-diz-nova-ministra-da-agricultura.shtml>. Acesso em: 22 maio 2015.

23 A carta pode ser conferida integralmente em: <http://www.socioambiental.org/sites/blog. socioambiental.org/files/nsa/arquivos/apib_qual_sera_a_marca_da_politica_indigenista_do_ governo_antiindigena.pdf>. Acesso em: 10 jan. 2015.

24 Ao ser perguntado, durante uma entrevista à Revista Cult, em agosto de 2015, sobre como ele avaliava a política indigenista do governo Dilma Rousseff, o antropólogo Eduardo Viveiros de Castro - um dos pensadores brasileiros com maior influência internacional - não hesitou em responder: "ignorante, arrogante e genocida". (disponível em: <https://pib.socioambiental.org/en/ noticias?id=155500\&id_pov=24>. Acesso em: 11 ago. 2017).

25 No dia 18 de janeiro de 2017, Moraes baixou a Portaria n 68, alterando o processo demarcatório das terras indígenas brasileiras. Ao final de um já longo e demorado processo institucional regulado pelo Decreto no 1.775 de 1996, a referida portaria acrescentaria a formação de um Grupo Técnico Especializado (GTE) para"subsidiar"o ministro nas decisões a serem tomadas relativas às demarcações. Este GTE, afirma o texto, seria formado por representantes da Funai, da Consultoria Jurídica, da Secretaria Especial de Direitos Humanos e da Secretaria de Políticas de Promoção da Igualdade Racial, e teria como prerrogativa a realização de "diligências" acerca de processos demarcatórios em fase avançada. Na prática, porém, o estabelecimento de mais esta instância no processo demarcatório funcionaria em moldes semelhantes ao do chamado "Grupão", um grupo de trabalho interministerial que funcionou durante quase toda a década de 1980 e que teve como efeito concreto, conforme muitos estudiosos do tema indicam, o virtual congelamento dos processos de reconhecimento territorial indígena no período. Esta portaria foi subsequentemente revogada no dia 19 de janeiro de 2017 (Soares, 2017).

26 O referido ministro afirmou em entrevista que "terra [indígena] não enche barriga de ninguém" (disponível em: <http://www1.folha.uol.com.br/poder/2017/03/1865209-ministro-da-justica-criticaindios-e-diz-que-terra-nao-enche-barriga.shtml>. Acesso em: 11 ago. 2017). 
institucional, em um contexto de tumultuadas trocas de comando deste órgão. ${ }^{27}$

Por fim, a discussão acerca da tese do marco temporal em discussão no Supremo Tribuna Federal parece configurar-se como um novo e forte fator de mobilização dos povos originários. Conforme a discussão aqui apresentada, podemos esperar novos ciclos de protestos de grupos indígenas para os anos vindouros.

\section{Referências}

ABERS, R.; SERAFIM, L.; TATAGIBA, L. Repertórios de interação estado-sociedade em um estado heterogêneo: a experiência na era Lula. DADOS - Revista de Ciências Sociais, Rio de Janeiro, v. 57, n. 2, p. 325-357, 2014.

ALCANTARA, C. Negotiating the deal: comprehensive land claims agreements in Canada. Toronto: Toronto University Press, 2013. ALONSO, A. Repertório, segundo Charles Tilly: história de um conceito. Sociologia \& Antropologia, v. 2, n. 3, p. 21-41, 2012.

ALONSO, A.; MISCHE, A. Changing repertoires and partisan ambivalence in the new Brazilian protests. Bulletin of Latin American Research, v. 36, n. 2, p. 144-159, 2016.

APIB - ARTICULAÇÃO DOS POVOS INDÍGENAS DO BRASIL. Quem somos. Brasília: Apib, 2012.

AVRITZER, L. (Org.) Experiência democrática, sistema político e participação popular. São Paulo: Editora Fundação Perseu Abramo, 2013.

- Os impasses da democracia no Brasil. Rio de Janeiro: Civilização Brasileira, 2016.

BRASIL. Constituição da República Federativa do Brasil. Brasília: Senado Federal, 1988.

BRINGEL, B. Com, contra e para além de Charles Tilly: mudanças teóricas no estudo das ações coletivas e dos movimentos sociais. Sociologia \& Antropologia, v. 2, n. 3, p. 43-67, 2012.

27 Disponível em: <http://www.correiobraziliense.com.br/app/noticia/politica/2017/05/06/internas_ polbraeco,593395/exoneracao-de-presidente-e-corte-de-verba-funai-esta-ameacada-de-exti.shtml>. Acesso em: 11 ago. 2017. 
CIMI - CONSELHO INDIGENISTA MISSIONÁRIO. Relatório Violência contra os Povos Indígenas no Brasil. Brasília: Cimi, 2012.

CUNHA, M. C. Índios no Brasil: história, direitos e cidadania. São Paulo: Claro Enigma, 2012.

FAJARDO, R. Y. De la tutela a los derechos de libre determinación del desarrolló, participación, consulta y consentimiento: fundamentos, balance y retos para su implementación. Amazônica, v. 1, n. 2, p. 368-405, 2009.

GOLDSTONE, J. A. Bridging institutionalized and noninstitutionalized politics. In: GOLDSTONE, J. A. (Ed.). States, parties and social movements. Cambridge: Cambridge University Press, 2003.

MARÉS, C. F. Multiculturalismo e direitos coletivos. In: SANTOS, B. S. (Orgs.). Reconhecerpara libertar: os caminhos do cosmopolitismo cultural. Rio de Janeiro: Civilização Brasileira, 2003.

NEVES, L. J. O. Olhos mágicos do Sul (do Sul): lutas contrahegemônicas dos povos indígenas no Brasil. In: SANTOS, B. S (Org.). Reconhecer para libertar: os caminhos do cosmopolitismo cultural. Rio de Janeiro: Civilização Brasileira, 2006.

OIT - ORGANIZAÇÃO INTERNACIONAL DO TRABALHO. Convenção $n^{\circ} 169$ sobre os Povos Indígenas e Tribais em Países Independentes. Genebra: OIT, 1989.

ONU - ORGANIZAÇÃO DAS NAÇÕES UNIDAS. Declaração das Nações Unidas sobre os Direitos dos Povos Indígenas. Nova Iorque: ONU, 2008.

RAMOS, A. R. Cutting through state and class: sources and strategies of self-representation in Latin America. In: WARREN, K. B.; JACKSON, J. E. Indigenous movements, self-representation and the state in Latin America. Austin: University of Texas Press, 2002.

(Org.). Constituições nacionais e povos indígenas. Belo Horizonte: Editora UFMG, 2012. 
RODRIGUES, A. T. Ciclos de mobilização política e mudança institucional no Brasil. Revista de Sociologia e Política, n. 17, p. 33-43, 2001.

SCHOLTZ, C. Negotiating claims: the emergence of indigenous land claim negotiation policies in Australia, Canada, New Zealand, and the United States. Abingdon-on-Thames: Routledge, 2006.

SOARES, L. B. Portaria paralisará demarcações de terras indígenas em fase avançada. Brasil de Fato, Belo Horizonte, 23 jan. 2017. Disponível em: <https://www.brasildefato.com.br/2017/01/23/ portaria-paralisara-demarcacoes-de-terras-indigenas-em-faseavancada/>. Acesso em: 11 ago. 2017.

TARROW, S. O poder em movimento: movimentos sociais e confronto político. Tradução de Ana Maria Sallum. Petrópolis: Vozes, 2009. . Strangers at the gates: movements and states in contentious politics. New York: Cambridge University Press, 2012.

TATAGIBA, L. 1984, 1992 e 2013: sobre ciclos de protestos e democracia no Brasil. Política \& Sociedade, v. 13, n. 28, p. 35-62, 2014.

TREJO, G. Etnia e mobilização social: uma revisão teórica com aplicações à "quarta onda" de mobilizações indígenas na América Latina. In: DOMINGUES, J. M.; MANEIRO, M. (Orgs.). América Latina hoje: conceitos e interpretações. Tradução de Silvia de Souza Costa. Rio de Janeiro: Civilização Brasileira, 2006.

VERDUM, R. Do orçamento como direito ao direito de consulta. In: CIMI - CONSELHO INDIGENISTA MISSIONÁRIO. Relatório Violência contra os povos indígenas no Brasil. Brasília: Cimi, 2011. WARREN, K. B.; JACKSON, J. E. Studying indigenous activism in Latin America. In:

(Eds.). Indigenous movements, self-representation and the state in Latin America. Austin: University of Texas Press, 2002.

\section{Resumo}

O artigo trata do repertório de ação do movimento indígena brasileiro entre 2009 e 2016, com foco no grande ciclo de protestos contra a aprovação da Proposta de Emenda Constitucional (PEC) 215/2000, 
que prevê a transferência de competência demarcatória de terras indígenas para o Congresso brasileiro. Coletamos e categorizamos todas as postagens realizadas nos sítios eletrônicos da Articulação dos Povos Indígenas do Brasil (APIB) acerca de sua atividade política no período e apresentamos os dados de forma descritiva. Concluímos que este movimento utiliza majoritariamente um repertório não contencioso, com destaque para sua forte utilização de meios digitais e divulgação em órgãos de imprensa, em todo o período analisado, e que vem declinando em termos quantitativos. As ações de protesto são de caráter multiétnico, ou seja, envolvem mais de uma etnia. Por fim, verificou-se que as ações do movimento concentram-se sobretudo em Brasília, seguida de Mato Grosso do Sul e do Amazonas.

Palavras-chave: movimento indígena; repertório; protesto; movimento social; PEC 215.

\section{Abstract}

The paper deals with the repertoire of action of the Brazilian Indigenous movement between 2009 and 2016 focusing on the cycle of protests the approval of the Constitutional Amendment Proposal 215/2000. This bill proposes the transference of demarcatory competence to the Brazilian Congress. We collected and categorized all the posts made on the websites of the Articulação dos Povos Indígenas do Brasil (APIB) about their political activity in the period. We conclude that this movement mainly uses a non-contentious repertoire, with emphasis on its active use of digital media and dissemination in the press throughout the analyzed period, which has been declining in quantitative terms. Protest actions are multiethnic in nature, meaning they involve more than one ethnic group. Finally, we verified that the actions of the movement are concentrated mainly in Brasília, followed by Mato Grosso do Sul and Amazonas.

Keywords: Indigenous movement; repertoire; protest; social movement; PEC 215.

Recebido em 15 de abril de 2017.

Aprovado em 15 de agosto de 2017. 